\title{
A ciência em ação: seguindo Bruno Latour
}

\author{
Science in action: following \\ Bruno Latour \\ Márcia de Oliveira Teixeira \\ Socióloga, mestre em ciências, pesquisadora-visitante do convênio Fiocruz/Faperj \\ Escola Politécnica de Saúde Joaquim Venâncio \\ Av. Brasil, 4365 Manguinhos \\ 21045-000 Rio de Janeiro - RJ Brasil \\ marciat@fiocruz.br/marciat23@hotmail.com
}

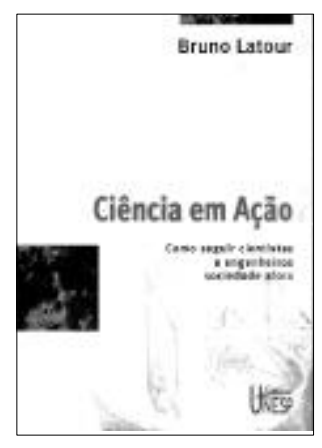

Bruno Latour

Ciência em ação:

como seguir cientistas

$e$ engenheiros

sociedade afora

São Paulo, UNESP,

2000 .
A recente edição em língua portuguesa do livro Ciência em ação: como seguir cientistas e engenheiros sociedade afora nos convida, a nós leitores brasileiros, à leitura de mais um trabalho de Bruno Latour. Particularmente, instiga-me saber por que, dentre tantos autores dos chamados estudos sociais da ciência, Latour tanto se destaca entre nós. Afinal este é o terceiro livro deste filósofo e professor do Centre de Sociologie de l'Innovation (CSI) ${ }^{1}$ aqui publicado. ${ }^{2}$ Muito embora, alguns haverão de retrucar, se trate de obras quase obrigatórias, uma vez presentes nas referências bibliográficas da maior parte dos trabalhos sobre as relações entre ciência, tecnologia e sociedade.

No entanto, Ciência em ação distingue-se de grande parte da produção anterior de Latour, lembrando que sua primeira edição, em língua inglesa, é de 1987 pela Havard University Press. Distingue-se por não ser um estudo denso de uma instituição de pesquisa ou de um fato científico, a exemplo dos precedentes Laboratory life (com Woolgar, 1979) e Les microbes: guerre et paix (1984). Não, aqui seguimos um Latour entretido com uma série de estudos de caso, alguns realizados por outros pesquisadores. ${ }^{3}$ Um Latour preso à tentativa de estabelecer as recorrências e as singularidades entre as situações e os contextos relatados nesses estudos, para então pensar nas problemáticas e métodos compartilhados por seus autores. Pensar, portanto, na possibilidade de um campo de pesquisa interdisciplinar dedicado às relações entre ciência, tecnologia e sociedade. Reivindicando, sobretudo, uma forma de análise não centrada no social nem só no técnico, porém capaz de respeitar a dinâmica não hierárquica e não-linear de suas imbricadas relações.

Projeto ambicioso, conduzido pelo autor para desembocar no estabelecimento de regras ("indico as decisões que são necessárias tomar a priori na consideração de todos os fatos empíricos criados pelas disciplinas especializadas") e princípios ("indico a minha síntese pessoal dos fatos empíricos em mãos após dez anos de trabalho nessa área”, 
p. 36). Porém, pensar neste projeto implica dizer algo acerca do campo com o qual Latour dialoga. ${ }^{4}$

O final da década de 1960 marca a produção de estudos que propõem um modo peculiar de tratar as tecnociências. Até então as ciências sociais, em especial a sociologia, circunscreviam sua discussão a algumas poucas temáticas, em geral presas ao processo de organização das instituições científicas, as políticas públicas, as relações com o setor produtivo e o militar e os conflitos com as formas de saber não científicas. Reunindo influências diversificadas, a sociologia dos conhecimentos científicos ${ }^{5}$ passou a entender estes conhecimentos como socialmente constituídos. Na década de 1970 , dois centros dominam a produção de estudos - Bath ${ }^{6}$ e Edimburgo. Neste último, organizou-se um dos mais destacados programas de pesquisa em sociologia do conhecimento. Designado como Programa Forte (Bloor, 1976), ele distinguiu-se como uma veemente defesa da análise sociológica dos conteúdos das teorias científicas, ${ }^{7}$ resgatando as contribuições de Durkheim (1979), Mannheim (s. d.) e Kuhn (1962).

A despeito das influências nos trabalhos sistematizados por Latour em Ciência em ação, é possível discernir rupturas, em certo sentido, profundas. Dimensões, muito pouco presentes nos estudos da sociologia dos conhecimentos científicos (e tecnológicos), despontam como fundamentais nos trabalhos empíricos da década de 1980. São elas as práticas cotidianas dos laboratórios e os materiais (não-humanos) nelas envolvidos. Torna-se também saliente a influência de outras abordagens sociais, cujas ênfases recaem na perspectiva microssocial (Pickering, 1992), a exemplo do interacionismo simbólico e da etnometodologia. Ciência em ação introduzse na discussão de um campo de estudos sociais da ciência. Trata-se de um outro programa de estudos, que compartilha referências, preocupações e a rejeição de uma perspectiva disciplinar. Porém, a exemplo dos demais programas, não pode ser entendido como um desdobramento linear e eminente.

Alguns poucos comentários se fazem necessários. As pesquisas sociológicas, ao buscarem o social nos conhecimentos científicos, o fazem em termos da identificação dos interesses de diferentes grupos sociais. A disputa e a associação de interesses, na definição de problemáticas e na legitimação de enunciados científicos, são privilegiadas. A análise pautase no contexto sociocultural, na dinâmica das redes sociais que sustentam a produção científica. Todavia, o movimento das redes de interesses sociais são insuficientes para explicar as práticas cotidianas da pesquisa (Callon, 1989b; Pickering, 1992). Autores como Latour (2000; 1979), Law (1989) e Callon (1989a) defendem que o entendimento dos processos sociais de produção da ciência deve comportar o entendimento das práticas realizadas nos laboratórios. É preciso entender as conexões entre o social e o tecnocientífico. Para tanto, salientam a simetria entre o social e a posição dos artefatos, das teorias e dos experimentos na produção da ciência ocidental. Propõem uma análise sociotécnica.

Assim, Ciência em ação pode ser interpretado como tentativa de enfrentamento de dois problemas: os limites da etnografia, respondendo se estudos locais de diferentes processos de produção de fatos tecnocientíficos podem nos dizer algo acerca do fazer científico; e o 
estabelecimento de um campo de pesquisa capaz de lidar com a dispersão das disciplinas e objetos das abordagens sociais das tecnociências (2000, p. 35).

O primeiro enfrentamento está diretamente associado à proposição de se analisar as práticas cotidianas da pesquisa científica. Estudar as tecnociências a partir de descrições densas dos laboratórios, a exemplo do realizado por Latour e Woolgar (1989) no Instituto Salk. Era preciso relatar o que ocorria nesses espaços, enfatizar o que produziu a diferença entre a ciência ocidental e outras formas de conhecimento, qual seja a manipulação de objetos, os experimentos, a fabricação de artifícios de deslocamento e de inscrição permitindo uma acumulação reflexiva. E aqui se inserem os trabalhos já citados de Latour, Woolgar, Law e Callon marcados pelo acentuado cunho etnográfico. Trabalhos reunidos nos chamados 'estudos de laboratório' (Knorr-Cetina, 1981).

Parte dessa produção aparece como material básico de pesquisa do livro em questão. Uma produção que se apóia em relatos minuciosos para levar a cabo seu objetivo de tratar a ciência do modo como ela acontece, como uma sucessão não-linear de práticas sociotécnicas. A etnografia forneceu assim os instrumentos e as formas de problematizar, que permitiram entender o modo como as táticas cotidianas de enfrentamento de problemas e de realização de atividades ocorrem. Permitiram também a discussão das relações entre grupos sociais externos ao laboratório, o "laboratório extenso" para Callon (1989b) ou a cidadela para Martin (1998); e os processos nele desenvolvidos. Um modo, enfim, de entender a forma assumida por essas práticas para a produção de conhecimentos e objetos tecnocientíficos. Os objetos e fatos são tratados como materializações de processos sociotécnicos. A atenção está voltada para o modo como esses processos são produzidos e atualizados. Porém, as análises não se restringem ao laboratório, fornecendo pistas e ferramentas conceituais para persegui-los (os processos) sociedade afora. Ao fazê-lo, supõem que esses processos jamais se esgotam no laboratório, não cessando também quando as "caixas-pretas" são fechadas. Pois os usos, tanto quanto as formas dos objetos e dos fatos, são definidos no interior das performances dos processos sociotécnicos.

O segundo enfrentamento combina a perspectiva interdisciplinar à diversidade de modos de lidar com os processos sociotécnicos - eles próprios muito diversos —, através da mistura de instrumentais e de influências teóricas. Em certo sentido, essa diversidade se revela na dificuldade de atribuir uma designação ao campo. Dificuldade que persiste até hoje, não obstante a disseminação da designação estudos sociais da ciência. Ao longo do próprio livro, há referências à antropologia da ciência, muito usada em Laboratory life e em outros trabalhos posteriores (Latour, 1985), mas também à ciência, tecnologia e sociedade. Essa oscilação parece-me interessante, porquanto nos fale da dificuldade de encontrar uma designação capaz de expressar as proposições desse campo, bem como das diferentes ênfases adotadas pelos programas de pesquisa social das tecnociências. Ênfases em tudo relacionadas à produção das ciências sociais nas décadas de 1970 e 1980 (Alexander, 1987; Machado, 1991), centrada em abordagens de cunho interpretativo, no estudo de situações locais e nos processos interacionais em lugar dos sistemas sociais. 
Logo na Introdução (p. 34), Latour sustenta a necessidade de um campo ampliado, constituído pelo compartilhamento de métodos e problemas. Contrapõem-se, portanto, as "tradicionais" abordagens sociais das ciências organizadas por disciplinas e objetos. Esta organização não permitiria entender o processo sociotécnico de produção de conhecimentos tecnocientíficos. Lembrando que esta produção é concebida por Latour como um processo social, cuja análise privilegia suas práticas e, com elas, novos problemas e objetos. Assim, os instrumentais, métodos, objetos e os trabalhos espalhados, até então, por tantas disciplinas passariam a circular por um espaço de interlocução e problematização comum. A sistematização de tantos estudos, levada a cabo por Latour, encontra na constituição desse espaço sua justificativa. Era preciso extrair as regras (metodológicas) partilhadas, únicas conexões que aliam abordagens e ênfases tão dispersas (p. 36). Regras capazes de subsidiar o estudo da ciência em ação, perseguindo a intensa movimentação entre os laboratórios, com os seus especialistas, e o exterior povoado por não-especialistas. Regras, por fim, capazes de explicar como os conhecimentos produzidos nos laboratórios alteram as experiências dos não-especialistas em seus próprios mundos sociais. E, em contrapartida, como esses mundos sociais alteram o fazer nos laboratórios.

É difícil tratar da posição da etnografia sem citar a influência, muito presente em Ciência em ação, da etnometodologia. ${ }^{8}$ A certa altura, lê-se: "eles sabem que, sem reescrever e recolocar tudo, a força do texto se esvairá" (p. 94), e "eles não usam a Natureza como árbitros externos, e não temos razões para imaginar que somos mais inteligentes que eles" (p. 164). Temos aqui aproximações com a sugestão etnometodológica de tomar os atores envolvidos com o mundo social como sociólogos em estado prático. Seria possível então entender a produção de conhecimentos científicos através das práticas laboratoriais cotidianas, por essas encerrarem métodos não formalizados. Encerram, por conseguinte, modos de fazer, interpretar e usar. Da análise do conjunto de práticas se depreende os métodos usados pelos cientistas para produzir conhecimentos e objetos tecnocientíficos; cabendo ao sociólogo a sistematização desses métodos (etnométodos), enfatizando suas incoerências, ambivalências e conflitos. Etnométodos que não correspondem ao discurso da ciência pronta. Estudar essas práticas sociotécnicas equivaleria à análise dos processos interpretativos e das experiências coletivas que as conformam. Processos que produzem decisões e táticas de negociação, as quais se estendem para fora do laboratório.

Latour, simultaneamente à sistematização e à discussão dos etnométodos, toma-os para si. Um modo de tratar Ciência em ação é tomá-lo como um caso exemplar dos princípios aí sistematizados. É tomá-lo, assim, como uma proposta de reflexão acerca da própria produção de conhecimentos sociológicos, como no último capítulo.

Interessar, construir alianças, produzir provas, mobilizar o maior número de aliados e endurecer as provas são estratégias usadas para volver uma ficção em fato. No dizer de Latour, para deslocar-se da face direita de Janus à esquerda (2000, p. 16). E nosso autor segue um percurso em tudo similar. Somos envolvidos pela sucessão de estudos de caso de diferentes áreas do conhecimento, em diferentes contextos e realizados por diferentes pesquisadores. Desmontar sua argumentação, a certa altura, 
implicaria seguir Callon em sua análise da controvérsia entre os engenheiros da EDF e da Renault, Law e o embate dos portugueses contra o Atlântico ou ainda Hughes e a eletrificação da sociedade americana. Exigiria um enorme esforço de mobilização de outras provas, novos documentos, novas análises de discurso e realização de outras entrevistas. Teríamos que nos apoiar na produção daqueles que desestabilizaram suas influências, produzindo um novo contexto de citações. O leitor é envolvido por conexões intricadas de argumentos, citações e referências. Produzir essas conexões é produzir coerências onde elas não estão dadas. É produzir provas, coisas para serem vistas, observadas, comparadas e confrontadas.

A discussão do exercício de produção dessas cadeias conduz à noção de tradução ${ }^{9}$ e ao tratamento dos laboratórios como centros de tradução. Essa noção permite pensar sobre muitas das proposições de Latour em Ciência em ação, ou seja, pensar na proposta do campo e em suas formas de análise. A noção expressa a simetria entre os microprocessos, que ocorrem no cotidiano das equipes, e as negociações que envolvem um universo dilatado de elementos e questões, reunindo outros especialistas e não-especialistas. Expressa assim a permeabilidade entre o lugar onde se realizam as práticas tecnocientíficas (o laboratório) e o seu entorno, materializando a possibilidade de se produzir análises simétricas, análises sociotécnicas. ${ }^{10}$ Contudo, a produção contínua de conexões não implica, necessariamente, que a tradução abarque processos lineares. Eles antes envolvem rupturas, alianças, conflitos e, sobretudo, a produção de mais ou menos diferenças entre elementos diferentes - entre humanos especialistas em C\&T e não-especialistas, entre humanos e não-humanos. Mesmo sendo possível pensá-la de modo mais genérico, de lhe atribuir uma definição, a tradução jamais é completamente descontextualizada, designando, a cada estudo, uma certa gama de processos e deixando de designar outros tantos.

Ao pensar em termos de tradução, penso também em como usá-la para lidar com o fazer tecnocientífico nacional. Como usá-la para tratar as relações entre as tecnociências e a sociedade, caso se pondere o quanto as redes sociotécnicas estão dilatadas nos estudos apresentados por Latour. Esse é um problema pertinente ao reconduzir à possibilidade de deslocar os produtos das análises antropológicas de seu contexto de produção. Assim, as traduções são extensas e diversas tanto quanto as situações estudadas o permitem. As traduções não são formadas desde o princípio por elementos de diferentes mundos sociais, conquanto não existam como realidades dadas esperando para serem mobilizadas. As conexões entre parlamentares, legisladores, grupos sociais e cientistas ocorrem ou não sempre de distintos modos. São sempre possíveis nunca absolutamente prováveis. Logo, elas podem vir a ser formadas por elementos muito diversos ou não. Cabe-nos, a cada estudo, a tarefa de procurar esses elementos, seus elos, as aproximações, as ligações transversais e as rupturas próprias a cada local. Cabe-nos também pensar em seus limites frente ao nosso próprio universo de relações.

Ao acentuar a diversidade de elementos reunidos nos processos de tradução, pondo a produção de conhecimento como uma ação eminentemente coletiva, torna-se inevitável dizer algo acerca dos humanos e não-humanos (materiais, equipamentos e artefatos de inscrição e armazenamento de dados). 
A possibilidade de conceder igual tratamento aos humanos e nãohumanos apóia-se na rediscussão do princípio da simetria propalado pelo Programa Forte (Bloor, 1976). Originalmente, colocava-se a necessidade de dar tratamento equivalente ao verdadeiro e ao falso, ao científico e ao social. Gradualmente houve uma ampliação. Influenciadas pela semiótica (Latour e Woolgar, 1989, Callon, 1989a' Callon e Law, 1995), as análises passam a se basear na equivalência entre humanos e não-humanos nos processos sociotécnicos. Essa equivalência apóia-se em três pontos: a inexistência de hierarquias a priori entre os humanos, os organismos biológicos de qualquer ordem e as coisas materiais; na impossibilidade de se apontar a priori diferenças entre os agenciamentos humanos e não-humanos; e na tecnificação da ciência e do próprio cotidiano das sociedades ocidentais (Woolgar, 1996; Callon e Law, 1995). ${ }^{11}$

No entanto, era preciso dispor de uma categoria capaz de comportar essa proposição (lidar com humanos e não-humanos de forma simétrica). Da interlocução com a semiótica se produziu a possibilidade de utilizar a de 'actantes', objetos discursivos e equivalentes entre si, capazes de designar uma pessoa, um animal ou máquina (Greimas, 1976, p. 84). Os actantes são definidos por Latour como qualquer coisa ou pessoa capaz de ser representada (op. cit., p. 138). É possível se recorrer a um dos exemplos dados por Latour.

O actante polônio é desconhecido, de início representado por reações aos ensaios experimentais. Ele é o conjunto de respostas produzidas ao longo das provas e contra provas mobilizadas no laboratório. Ele é as suas diferentes performances no interior do conjunto de práticas experimentais. Suas delimitações são-lhes atribuídas no interior das operações de tradução (experimentos e suas análises). Os actantes (fatos e objetos tecnocientíficos) são tomados como entidades não delimitadas a priori. Suas formas, seus sentidos, atributos e possíveis usos são sempre definidos no interior das redes sociotécnicas. Reafirma-se, por conseguinte, a impossibilidade de tratar contexto e conteúdo de modo autônomo, bem como de tomar as delimitações como substantivas (Cassirer, 1997).

No entanto, a categoria não redunda na solução dos problemas advindos com a proposição de lidar simetricamente com os não-humanos nos processos sociotécnicos. Muito depois da publicação de Ciência em ação, o desafio permanece sendo como operar essa proposta (Woolgar, 1996), como efetuar análises descentradas dos humanos. Seguindo Cassirer, o desafio é responder se seria possível pensar em algo ou de forma não antropocêntrica (Teixeira, 1997).

A discussão dos não-humanos pode conduzir a outras indagações pertinentes à análise local das tecnociências. Por exemplo, à acessibilidade dos laboratórios aos não-humanos, em sua ampla maioria importados. E, de algum modo, os equipamentos e materiais estão imbricados à agenda de pesquisa e essa aos interlocutores internos e externos ao laboratório. Interlocutores capazes de viabilizar a organização dos laboratórios, em torno do como e do que deve ser adquirido. Qual a identidade desses interlocutores (agências de fomento, pares, gestores) e como se relacionam com os laboratórios? Como são definidas as agendas de pesquisa e com elas as provas, os ensaios, os equipamentos necessários? Partindo-se dos 
não-humanos é possível perseguir a constituição e dinâmica das operações de tradução no interior dos laboratórios.

Como último ponto, acredito ser interessante indagar para quem Latour escreveu esse livro. Pois, se seus aliados e alguns interlocutores podem ser rastreados com relativa facilidade, o mesmo não se aplica a quem Ciência em ação se dirige. Outra singularidade desse livro, caso se tome outros trabalhos como referência, é a linguagem adotada - não esquecendo, todavia, que sua produção se deu em um período de efervescência e mutação da produção discursiva das ciências sociais em geral. Por vezes, ele adquire um tom de divulgação científica, como se seu propósito fosse sistematizar e discutir os métodos observados em diversos estudos, tornando-os acessíveis ao público, aos leigos. Não só seguir engenheiros sociedade afora, mas ir além, levando adiante a discussão de suas práticas. Afinal o público leigo, com o qual Latour insiste em se identificar ao longo do texto, também não é ator dos processos sociotécnicos?

\section{$\mathcal{N O} \mathcal{A} \mathcal{A}$}

1 O CSI está ligado à École Supérieure des Mines de Paris.

2 Jamais fomos modernos, Rio de Janeiro, editora 34, 1994; A vida de laboratório: a construção dos fatos científicos (com Steve Woolgar), Rio de Janeiro, Relume Dumará, 1997.

${ }^{3}$ Encontramos, por exemplo, referências ao estudo de Callon (1989a) sobre o veículo elétrico e ao de Law (1989), em torno das navegações portuguesas.

${ }^{4}$ Não se deve esquecer o funcionário público antenado e preocupado com a produção tecnocientífica francesa diante de seus pares ingleses, alemães, mas, sobretudo, americanos e japoneses. Sobre isso, ver Callon e Latour (1986).

${ }^{5}$ Em inglês é comum a utilização da sigla SSK. Já na década de 1980, a extensão "e tecnológico" é incorporada, indicando a ampliação dos programas de pesquisa.

${ }^{6}$ A universidade de Bath abrigou, entre outros autores, Harry Collins, cuja ênfase dada à perspectiva microssocial também influenciará a produção posterior de Latour, Callon e Law.

7 Cabe observar que Latour foi o mentor, na década de 1980, da Coleção Pandore editada pela La Découverte, cujo objetivo era tornar a produção destes centros acessível na França.

${ }^{8}$ Ver textos reunidos em Pickering (1992), para ter uma visão da influência da etnometodologia e da semiótica francesa nos estudos, bem como de sua crítica.

${ }^{9}$ E não translação. Provavelmente o maior pecado dessa tradução, sobretudo quando já se dispunha de uma edição de Jamais fomos modernos onde a categoria aparece corretamente traduzida, além de outros trabalhos nacionais que a discutem e utilizam.

${ }^{10}$ A tradução a princípio pode ser tomada como ato de produção das redes sociotécnicas. Porém, no geral, passou a ser empregada como equivalente a rede (Latour, 1994).

${ }^{11}$ Há uma infinidade de estudos desse processo, mas sabemos pouco de sua dinâmica entre nós: onde estão e como são as nossas diferenças?

\section{REFER̂ETCIAS BIBLIOGRÁFICAS}

Alexander, J.

Bloor, $\mathcal{D}$.
'O novo movimento teórico'.

Revista Brasileira de Ciências Sociais, 2, 4, pp. 5-28.

Sociologie de la logique ou les limites de l'epistémologie.

Paris, Pandore. 
Callon, M. e Law, J. 1995

Callon, $\mathcal{M}$. 1989a

Callon, $\mathcal{M}$. $1989 b$

Callon, M. e Latour, B. 1986

Cassirer, Ernst

1997

Durkheim, E. 1979

Greimas, A. J. 1976

Knorr-Cetina, Karen 1981

Kuศn, $\tau$. 1962

Latour, Bruno 1994

Latour, Bruno 1990

Latour, B. e Woolgar, S. 1989

Latour, Bruno 1985

Law, J. 1989

Machado, Carlos S. 1991

Mannheim, $K$. s. d.

Martin, Emily 1998

Pickering, Andrew 1992

Teixeira, Márcia 1997

Woolgar, Steve 1996
'Agency and the hybrid collectif'. South Atlantic Quarterly, 94, pp. 38-76.

'Society in the making: the study of technology as a tool for sociology analysis'. Em W. Bijker; H. Thomas e P. Trevor, (orgs.), The social construction of technological systems. Londres, MIT Press.

'L'agonie d'um laboratoire'. Em La science et ses réseaux.

Paris, La Découverte.

'Comment suivre les innovations: clefs pour l'analyse sociotechnique'. Prospective et Santé, 36: 13-25.

Ensaio sobre o homem - introdução a uma filosofia da cultura humana. São Paulo, Martins Fontes.

Les formes élémentaires de la vie religieuse.

Paris, PUF.

Semiótica e ciências sociais.

São Paulo, Cultrix.

The manufacture of knowledge: an essay on the constructivist and contextual nature of science. Oxford, Pergamon.

The structure of scientific revolutions.

Chicago, Chicago University Press.

Jamais fomos modernos.

Rio de Janeiro, editora 34.

La science en action.

Paris, Pandore.

La vie de laboratoire: la production des faits scientifiques.

Paris, Pandore.

'Les vues de l'esprit'. Culture Technique, 14: 5-29.

'Technology and heterogeneous engineering: the case of portuguese expansion'. Em W. Bijker; H. Thomas e P. Trevor (orgs.),

The social construction of technological systems. Londres, MIT Press.

Cientistas e engenheiros em ação: um perfil da antropologia das ciências e das técnicas de Bruno Latour.

Dissertação de mestrado, Rio de Janeiro, COPPE/UFRJ.

Sociologia do conhecimento.

Porto, Rés.

'Anthropology and the cultural study of science'.

Science, Technology \&ु Human Values, 23: 1, pp. 24-45.

'From science as knowledge to science as practice'.

Em Science as practice and culture.

Londres, The University of Chicago Press.

O lugar dos não-humanos na construção do mundo: um diálogo entre Cassirer e os Estudos de Ciência e Tecnologia. (mimeo.)

'O fim da cognição? Os Estudos da Ciência e Tecnologia desafiam o conceito de agente cognitivo’.

História, Ciências, Saúde - Manguinhos, vol. II, no 3, pp. 105-33. 


\title{
As pessoas mais frágeis
}

\author{
The weakest persons
}

\author{
Ricardo Waizbort \\ Biólogo, pesquisador da Casa de Oswaldo Cruz \\ Av. Brasil 4365 \\ 21045-900 Rio de Janeiro - RJ Brasil \\ ricw@coc.fiocruz.br
}

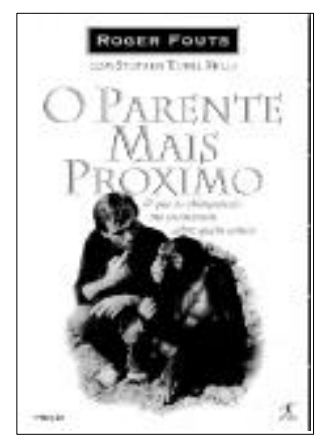

Roger Fouts

$O$ parente mais próximo: o que os chimpanzés me ensinaram sobre quem somos

Rio de Janeiro Objetiva, 1998
Tas últimas décadas, o desenvolvimento do debate sobre o direito 1 dos animais tem levado pesquisadores de todo mundo a refletirem sobre a ética do uso de seres vivos em experimentos científicos. O parente mais próximo: o que os chimpanzés me ensinaram sobre quem somos, de Roger Fouts, leva essa discussão às suas conseqüências filosóficas e morais mais agudas. Embora seja uma magnífica obra de divulgação científica, e tenha ficado umas poucas semanas entre os livros mais vendidos na categoria não-ficção, tudo que é sólido desmancha no ar: atualmente seus argumentos pouco despertam comentários, tanto entre os estudiosos de biologia e antropologia, quanto em outras áreas do conhecimento humano. O pretensioso alvo dessa nota é tentar sacudir o público dessa sonolência.

Produzido em parceria com o escritor de divulgação científica Stephen Tukel Mills, O parente mais próximo narra a trajetória do graduado em psicologia infantil Roger Fouts (e tangencialmente também a trajetória de sua esposa e as dos seus três filhos) desde que ele próprio se engajou no Projeto Washoe, em 1967, como estudante de pós-graduação que almejava ajudar crianças autistas. Washoe é a chimpanzé (Pan troglodytes) que Allan e Trixie Gardener adotaram em 1966 quando o bebê não-humano tinha cerca de dez meses de idade. O projeto: ensinar-lhe uma linguagem de sinais, ao contrário dos severos paradigmas behavioristas, em um ambiente rico em estímulos. Não era exatamente o trabalho que Fouts procurava na época, mas ele tinha que pagar a universidade em que estudava, e Washoe literalmente atirou-se nos braços dele quando o viu pela primeira vez.

Desde pelo menos Platão e Aristóteles os seres humanos se consideraram como as únicas criaturas da Terra capazes de desenvolver uma linguagem. Até aproximadamente metade do século passado, muitos europeus e americanos cientificamente cultos acreditavam que animais e plantas estavam todos organizados em uma grande cadeia de seres construída por Deus, direta ou indiretamente. Naturalmente o ser humano ocuparia o ápice dessa cadeia, no cume da perfeição e da complexidade. Somente a ele teria sido dado o dom da inteligência (atributo da divindade) e da fala. Deduz-se então que seria tolice imaginar que macacos pudessem falar, pensar ou se emocionar pois eles pertenceriam ao reino das bestas brutas, das máquinas cartesianas feitas por Deus para proveito humano.

Em 24 de novembro do ano de 1999, A origem das espécies de Charles Darwin completou 140 anos: vida longa para essa alta realização do espírito humano! A obra é considerada um marco nas ciências biológicas não 
apenas por aprofundar vertiginosamente nosso conhecimento sobre o incomensurável fenômeno da evolução, mas também porque pela primeira vez um texto nas ciências biológicas ofereceu uma explicação causal e mecânica sobre a origem e a diversidade das espécies, sem apelar para qualquer raciocínio que envolva a idéia de Deus. Um corolário da idéia darwinista de evolução por seleção natural é que a própria espécie humana descenderia de outra espécie, muito provavelmente extinta há alguns milhões de anos.

Muitos cientistas e filósofos da ciência têm reexaminado o darwinismo sob uma aguda visão crítica praticamente desde que a idéia de evolução foi promulgada à época da primeira edição de A origem das espécies. Existe muita discordância acerca da teoria da evolução, sendo talvez a mais notória a controvérsia sobre a seleção natural como causa da evolução. A seleção natural é uma causa suficiente e necessária à evolução? A seleção natural é apenas a projeção subjetiva da mente humana ao problema da diversidade das espécies? As respostas a essa questão são por vezes contraditórias. Atualmente os darwinistas mais ortodoxos (os neodarwinistas e os adeptos da teoria sintética da evolução) afirmam que a seleção natural é uma causa importantíssima, no mínimo, enquanto outros cientistas (biólogos, antropólogos etc.) negam uma função primordial para esse mecanismo. Note-se que ninguém nega que a evolução tenha existido, mas se discute muito, nem sempre educadamente, sobre sua causa (seleção natural) ou causas (seleção natural, mutação, deriva genética, catástrofes, divisões geográficas no espaço). A evolução é um fato para os cientistas. É também um fato a tentativa científica de descobrir, a partir de registros fósseis e outras informações imperfeitas, uma história narrativa que descreva como uma determinada espécie ou linhagem se originou de outra mais antiga. Além da evolução dever ser interpretada como fato e como história, como já se disse, a teoria da evolução também é uma teoria sobre as causas da evolução.

Antropólogos e biólogos reconhecem atualmente que há cinco ou seis milhões de anos os ascendentes do que seriam os homens e os chimpanzés de hoje começaram a se separar. As causas dessa separação são muito controvertidas. A história narrativa hoje paradigmática conta que por causa de uma drástica mudança de clima no Nordeste africano o ambiente em que vivia o ancestral comum do homem e dos chamados grandes macacos africanos (chimpanzés e gorilas) teria se modificado. Um novo cenário se originou: à antiga floresta tropical, no litoral Nordeste da África, se sobrepõem lentamente as savanas abertas. Imagina-se que pelo menos uma população do suposto ancestral comum que vivia mais próximo ao litoral foi obrigada a descer das árvores das florestas (que rareavam à medida que o clima ia se modificando) e ir viver nessas savanas abertas. No interior, onde o aparecimento progressivo da barreira geográfica não alterou em profundidade o ambiente florestal, evoluíram, a partir do mesmo ancestral, os atuais gorilas e chimpanzés. Darwin alegou em A origem do homem, publicado em 1871, que poderíamos encontrar rudimentos de linguagem nesses grandes primatas além da fabricação de ferramentas rudimentares.

As idéias darwinistas sobre o fato da evolução (a constatação que as espécies não são fixas, que estão se modificando no tempo geológico) e 
sobre a historicidade da evolução (a descoberta de uma classificação natural para os seres vivos baseada em uma perspectiva histórica, ou seja, por relações de parentesco) são amplamente aceitas. Entretanto, fora dos meios acadêmicos e profissionais mais restritos, o homem continua agindo cartesianamente como se animais e plantas, e outros recursos vivos e inanimados, estivessem no mundo à mercê dessa mesma humani-dade. Nesse contexto, O parente mais próximo leva a sério as questões darwinistas para provar que os chimpanzés também são pessoas, com personalidade e sentimentos diferenciados em cada um dos indivíduos.

Ao contrário dos behavioristas, os pais adotivos de Washoe, Allan e Trixie Gardener (Fouts se considerava como um irmão mais velho da chimpanzé), acreditavam que os chimpanzés poderiam aprender uma linguagem de sinais se não fossem privados de calor social (com membros de sua própria ou de outra espécie próxima, como a dos humanos). A tese era a de que os chimpanzés estavam justamente fazendo isso, sinalizando, muito antes, milhões de anos antes do homem utilizar a linguagem verbal.

Quando Fouts conheceu Washoe ela vivia em um quintal no fundo da casa dos Gardener há pouco mais de um ano. Washoe já tinha aprendido cerca de duas dúzias de sinais em ASL (American Signal Language - linguagem norte-americana de sinais ou ainda Ameslan). A pequena macaca já sinalizava com alguma desenvoltura. A linguagem americana dos sinais é uma linguagem de gestos feitos pelas mãos. Uma das principais tarefas de Fouts, como aluno de pós-graduação, era ensinar mais ASL para Washoe. E Fouts acabou tornando-se um estudioso em comunicação animal, com artigos publicados em revistas importantes e especializadas. Tornou-se também um grande amigo e admirador de Washoe, sem nenhuma ironia. Durante toda sua vida, Washoe dominaria mais de uma centena de signos com uma sintaxe bastante bem elaborada, sendo capaz de criar novos significados para as palavras, assim como produzir variações pessoais do modo de representar determinadas idéias.

Embora a narrativa da vida de Washoe seja divertida e dramática, sua história ganha cores muito mais vivas quando ela é transferida do quintal dos Gardener para Oklahoma, para a ilha do dr. Lemmon. Experimentos científicos utilizam chimpanzés em testes muitas vezes perversos e o dr. Lemmon era um dos inúmeros adeptos da crença de que "os animais são criaturas sem mente, cujo comportamento rígido, ao contrário dos seres humanos, é controlado pelos instintos" (p. 21). Conseqüência desse modo de ver as coisas é que animais como chimpanzés, mas também centenas de espécies de animais (mamíferos e outros), são submetidos a toda sorte de sofrimento. Eis um breve resumo:

Ao longo dos últimos quarenta anos, rodopiamos chimpanzés em aparelhos de força centrífuga e os lançamos no espaço. Esfacelamos seus crânios com barras de aço e os usamos como bonecos em testes de acidentes. E os privamos de qualquer contato materno, levando-os à psicose. Eles foram usados para testar pesticidas mortíferos e solventes industriais causadores de câncer. Foram também inoculados com doses maciças de poliomielite, hepatite, febre amarela, malária e HIV (p. 367). 
A luta de Fouts pode ser interpretada como uma tentativa de resolver alguns dos problemas da utilização de chimpanzés em experimentos. Uma investigação na estrutura superficial do livro, sua estrutura de três partes, revela a posteriori a evolução dos lares de Washoe e dos Fouts. Primeira parte: o quintal da casa dos Gardener para Washoe na cidade de Reno, estado de Nevada (1966-70); a ilha do dr. Lemmon, cidade de Norman no estado de Oklahoma (1970-80); o Centro de Pesquisa na cidade de Ellensburg, no estado de Washington (1989-97).

Apesar de suas condições brutais, é na ilha do dr. Lemmon que Washoe faz seus primeiros contatos com outros de sua espécie. Até partir do quintal dos Gardener em Reno, ela conhecera apenas humanos. Quando Washoe chega a essa cruel morada, ela e Fouts encontram outros chimpanzés que também sinalizavam em ASL. Esses são os tempos mais sombrios para Fouts: os tempos do fim da infância e o início da adolescência de Washoe; do conflito com o dr. Lemmon (que constrangia física e moralmente os macacos para que eles o temessem e obedecessem, como o personagem do inumano cientista que dá seu nome para A ilha do dr. Moreau); da batalha com as agências de financiamento do governo e com as instituições que utilizam chimpanzés para testes em suas pesquisas; de seu próprio mergulho na escuridão e no álcool. Mas é também esse o tempo em que Fouts abandona a perspectiva de ser um grande cientista e torna-se, depois de superada intensa crise, um lutador da causa de que não temos o direito de infligir dor física e moral aos chimpanzés ou a qualquer outra animal. É durante a permanência de Washoe na ilha que Fouts compreende estar em jogo muito mais do que apenas a sua carreira profissional, mas a vida, e talvez a morte, de indivíduos não-humanos capazes de sentir, pensar e sofrer como ele mesmo. Nessa altura emergem a complexidade, a plasticidade e a unicidade da mente animal e de sua profunda ligação biológica e cultural com a mente humana.

Felizmente Washoe vive hoje em um ambiente social mais rico e menos constrangedor do que a ilha do dr. Lemmon. Os Fouts conseguiram adotar um bebê chimpanzé para ela, depois que ela perdeu sucessivamente duas crias na ilha (uma das quais, por responsabilidade direta do dr. Lemmon). Washoe e Loului mais três outros chimpanzés, Dar (macho), Moja e Tatu (fêmeas), vivem em um ambiente certamente artificial, mas muito menos opressivo.

Mas o final da história não é feliz. Ademais, como se trata da narrativa de uma história real, não há um final para ela. A luta dos Fouts continua e vem dando resultados. Eles conseguiram criar o Instituto de Comunicação Chimpanzé e Humana onde vivem atualmente Washoe e sua família. O instituto possui um teto de tela metálica, com a altura de três pavimentos, ao ar livre, que permite que os chimpanzés se balancem por cima do espaço em que vivem, como fazem na floresta tropical úmida. Mas Fouts sabe que conseguiu salvar cinco chimpanzés de um negro futuro. Todavia, quantos chimpanzés hoje, agora, estarão sendo tirados ainda filhotes de suas mães para os fins mais escusos? Quantos outros animais estão sendo torturados sem nenhuma consideração por sua dor física e quem sabe psicológica? Temos razão para nos acharmos, humanos, os únicos possuidores de mente sobre a terra? 
As respostas de Fouts são darwinistas, ou melhor, neodarwinistas. Os chimpanzés são nossos parentes mais próximos e mais frágeis. Muito do que julgamos específico da humanidade deve ter lentamente emergido do mundo animal. Se Washoe é capaz de sinalizar em ASL é porque os gestos fazem parte de uma herança que ela trouxe da selva, como demonstram observações feitas sobre chimpanzés selvagens, como o livro Uma janela para a vida: 30 anos com os chimpanzés da Tanzânia, de Jane Goodall (Rio de Janeiro, Zahar, 1999).

Ao demonstrar que Washoe e sua família ampliada não só usam ASL como desenvolvem um pensamento abstrato, um raciocínio lógico, uma sintaxe elaborada, além de estratégias imprevistas para combinar os signos gestuais de forma inesperada, Fouts sustenta de forma irrefutável que Washoe e os chimpanzés em geral, não privados de contato social e condições dignas, são mestres na arte da comunicação simultânea (gestual).

Para Darwin, a linguagem estaria firmemente enraizada na anatomia, na cognição e no comportamento neuromuscular de nossos ancestrais primatas em comum. Como bebês, começamos gesticulando, não falando. A origem da fala está nos gestos, segundo Fouts. Todavia, nós seres humanos desenvolvemos espetacularmente a linguagem seqüencial (verbal, linear). Essa é uma linguagem que certamente nem os chimpanzés selvagens nem nenhum outro animal além de nós conseguiu desenvolver. Em nome dessa diferença ergueremos de novo uma barreira entre nós e o mundo vivo dizendo que a linguagem verbal, linear, nos foi dada como um dom divino, nos isentando da responsabilidade da dor alheia?

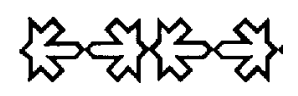




\title{
A peculiar medicina dos gaúchos \\ The distinctive medicine of the gauchos
}

\author{
Flavio Coelho Edler \\ Pesquisador da Casa de Oswaldo Cruz \\ Av. Brasil, 4365 \\ 21045-900 Rio de Janeiro - RJ Brasil \\ edler@coc.fiocruz.br
}

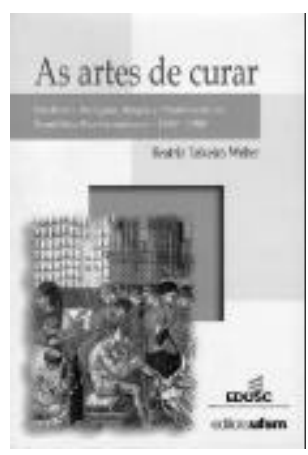

Beatriz Teixeira Weber

As artes de curar: medicina, religião, magia e positivismo na República Rio-Grandense 1889-1928

Santa Maria/Bauru, Editora da UFSM/ EDUSC, 1999
$\mathrm{N}^{a}$ a paisagem sociocultural do século $\mathrm{XX}$, as profissões apareceram como criaturas naturais, dotadas de legítima autoridade para influenciar ou mesmo dirigir os negócios humanos. Cada expertise reivindicava especial competência técnico-científica sobre a definição, avaliação e solução de nossos problemas cotidianos em áreas cada vez mais amplas. A medicina era geralmente apresentada como o arquétipo das profissões. Nela encontraríamos a forma mais bem-acabada de poder profissional. A demonstração da espetacular simbiose entre razão científica e ética de serviço tem sido a tônica de toda uma tradição historiográfica voltada a cultuar e justificar a autoridade que ela hoje goza, como sistema de conhecimentos e práticas dedicado a evitar, curar ou atenuar doenças.

Muita tinta tem sido gasta também na denúncia dessas formas de poder secular que se espalharam pelas sociedades modernas como contraponto do fenômeno que Weber cunhou como desencantamento do mundo. Da inspirada boutade de Oscar Wilde, para quem "toda profissão é uma conspiração contra os leigos" à "sociedade disciplinar" de Foucault, excelentes análises revelaram como as profissões lograram monopolizar o acesso e a aplicação do conhecimento que haviam adquirido, tendo em vista a preservação do status e de privilégios por elas reclamados. Dessa forma, toda uma vertente de estudos históricos e sociológicos dedicou-se à análise da influência política e cultural das profissões, buscando esclarecer a relação entre as profissões, as elites políticas e econômicas e o Estado; as relações entre elas, o mercado e o sistema de classes no mundo moderno.

No Brasil, desde fins da década de 1970, muitos autores debruçaramse sobre o nosso passado médico, com o fim de rever as representações laudatórias e enobrecedoras do desenvolvimento progressivo da ciência médica. Nessa empresa, puseram em foco a interação entre medicina e poder estatal, pretendendo comprovar uma homologia entre o discurso médico higienista e a estratégia de dominação das elites agrárias, tendo como pano de fundo o processo de aburguesamento da sociedade patriarcal. Apesar de terem contribuído para alterar definitivamente a imagem ascética e progressista do conhecimento médico, apresentandoo como um dos fermentos da ideologia conservadora com que se plasmou o modelo antidemocrático e hierárquico de nossa sociedade, estes estudos pioneiros tiveram uma limitação metodológica que lhes comprometeu o alcance analítico: em geral, tomaram como institucionalizado o conhecimento formalmente produzido e veiculado no estreito ambiente acadêmico. Entretanto, a análise dos textos científicos e técnicos não 
pode substituir a análise das diversas formas de interação humana que os cria e transforma no curso de sua utilização como empreendimento prático. A própria institucionalização requer a transformação do conhecimento por aqueles que o empregam. Justamente nesse ponto encontra-se um dos méritos do livro de Beatriz Teixeira Weber.

As artes de curar: medicina, religião, magia e positivismo na República Rio-Grandense - 1889-1928, originalmente uma tese de doutoramento defendida no Programa de História Social da Unicamp, trata das "mudanças ocorridas ... na forma como as autoridades públicas, médicos e instituições religiosas se relacionavam com práticas populares de cura”, no cenário gaúcho, durante a República Velha. Em contraste com as abordagens que estudam o exercício do poder médico informadas por conceitos teleológicos, excessivamente abrangentes e totalizantes, como medicalização ou profissionalização, Beatriz Weber procura resgatar a diversidade das práticas de cura numa sociedade marcada pela intensa desigualdade social à qual se somava uma pluralidade étnica, formada por imigrantes europeus de várias nacionalidades, índios e ex-escravos de origem africana.

Como sabemos, ao longo da segunda metade do século XIX a medicina hospitalar de base anatomoclínica, em interação com diversas disciplinas laboratoriais, fixaria um padrão de formação acadêmica, obtendo o monopólio legal da prática de diagnóstico, cura e profilaxia em quase todas as nações ocidentais. $\mathrm{O}$ controle desse conhecimento e de suas formas de aplicação implicou o domínio daqueles que a ele se opuseram. Ora, monopólio sem liberdade é fácil, mas como seria o processo de legitimação profissional dos doutores diplomados se não contassem com o poder de polícia do Estado para constranger ou erradicar a concorrência de outros curadores? O caso estudado pela autora permite tomar tal questão não como uma especulação teórica, mas, ao contrário, como um exemplo raro em que os esculápios tiveram que enfrentar outras concepções de cura e saúde vinculadas a distintas práticas culturais num ambiente de tensões e conflitos, sem proteção legal. De fato, o Rio Grande do Sul foi o único estado da federação a adotar uma perspectiva positivista após a proclamação da República, consolidada na Constituição Estadual de 1891. Um dos princípios norteadores dessa constituição garantia ampla liberdade profissional.

Debruçando-se sobre variada documentação - processos criminais, jornais e revistas de ampla circulação, legislação estadual e municipal, relatórios da provedoria da Santa Casa da Misericórdia de Porto Alegre, correspondências e relatos de irmãs franciscanas, crônicas e memórias deixadas por médicos e membros do governo estadual, publicações do Apostolado Positivista —, Beatriz Weber recupera as suposições, esperanças, necessidades, aspirações e interesses das pessoas comuns envolvidas com práticas alternativas à medicina acadêmica.

Curandeiros, mezinheiros, pajés, espíritas, feiticeiras, membros de ordens religiosas e parteiras populares confrontam-se com os médicos homeopatas e alopatas, oferecendo seus serviços à sombra dos poderes estatais que se recusavam a intervir no caminho inexorável da sociedade, em sua marcha rumo ao estado positivo. Não caberia ao governo imiscuirse nesse processo, apadrinhando uma ou outra prática, mas deixar que 
os indivíduos distinguissem livremente entre os preceitos científicos e as crendices fundadas em preconceitos metafísicos. Os membros do Partido Republicano Rio-Grandense, que monopolizaram o poder ao longo da Primeira República, garantiram a continuidade dessa perspectiva voltada a "zelar pelas condições materiais exigidas pela saúde pública e pela assistência voluntária, mas sem nunca ferir a liberdade individual, de consciência".

Dividido em quatro capítulos, o livro dedica-se, inicialmente, a explorar a visão de saúde que norteava a política oficial, recuperando as ambivalentes orientações defendidas por grupos de positivistas filiados a distintas correntes do comtismo. O segundo capítulo reflete sobre as relações entre a profissão médica e o governo gaúcho, tendo como fio condutor o processo de constituição da solidariedade corporativa, num contexto em que a própria medicina acadêmica estava envolvida em conflitos internos sobre a cientificidade de seus fundamentos e procedimentos técnicos de diagnóstico e terapêutica. Nesse momento, a criação da Faculdade de Medicina iria permitir que os doutores gaúchos iniciassem "uma guerra de trincheiras" pela afirmação de seus saberes face às ordens religiosas, que controlavam o hospital da Santa Casa, e à política positivista. O capítulo seguinte concentra-se no estudo da Santa Casa, instituição hospitalar e asilar de grande importância para a história médica local. Como a Santa Casa tinha funções assistenciais e, gradativamente, adquiriu funções terapêuticas e de produção de conhecimento médico, foram muito complexas e heterogêneas as relações entre os provedores leigos, que a administravam; as irmãs de caridade, que realizavam o trabalho de enfermagem e conforto espiritual; os médicos, que a punham no centro da formação profissional, ampliando e aproximando os vínculos entre ela e a Faculdade de Medicina; e os pacientes, que possuíam diversas crenças e perspectivas religiosas, compartilhando, entre si, o medo das práticas terapêuticas. Usando documentação original, Beatriz Weber vai analisando os significados da instituição para cada um desses grupos. A lenta afirmação do poder médico sobre os demais atores se deu em meio a "tensões e harmonias geradas pelo convívio de elementos aparentemente contraditórios, como fé e ciência, magia e clínica". Sua pesquisa desmente a visão arquetípica de uma medicina fortemente disciplinadora, persuasiva e destituída de opositores. Pelo contrário, a inscrição dos doutores num espaço dominado por irmãs religiosas revela que o exercício de seu poder profissional era compartilhado, negociado e mitigado devido à existência das vozes dissonantes bradadas por outras práticas curativas.

O quarto e último capítulo investiga justamente o universo das práticas populares de cura. Esse rico inventário, que inclui terreiros de batuques, rituais afro-brasileiros, seitas radicais de imigrantes europeus, benzedeiras, curandeiros, espíritas e parteiras, é analisado em seu permanente convívio com a medicina acadêmica. Weber demonstra sobejamente, "à luz da experiência dos gaúchos", que os saberes populares nem sucumbiram nem apenas reagiram ao controle do saber dominante. $O$ exame cuidadoso da prática desenvolvida por cada grupo que reclamava competência na solução de problemas ligados ao bem-estar físico e conforto material e espiritual daquela população - em especial feiticeiros, parteira e espíritas 
— torna evidente o quanto eles interagiram com criatividade, instituindo novas práticas sociais, e participaram ativamente das definições de saúde, doença e cura, ligadas a segmentos daquela sociedade.

Apresentado numa narrativa que informa e convence o leitor, o livro de Beatriz Weber vem preencher uma lacuna na história da medicina brasileira, geralmente restrita aos casos supostamente exemplares do Rio de Janeiro e da Bahia, onde a tradição médica firmou-se inicialmente. Trata-se, enfim, de uma obra inovadora, cuja narrativa fluente interessará também ao público não especializado.

\title{
Ligações perigosas: as relações entre Estado e ciência no Brasil do pós-guerra
}

\section{Liaisons Dangereuses: relations between the State and science in post-war Brazil}

\author{
Sérgio Gil Marques dos Santos \\ Fundação Oswaldo Cruz/Presidência \\ gsergio@terra.com.br
}

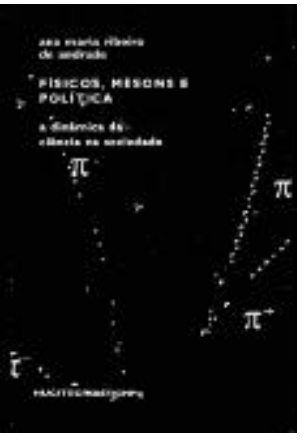

Ana Maria Ribeiro de Andrade

Físicos, mésons e política: a dinâmica da ciência na sociedade São Paulo/Rio de Janeiro, Hucitec/Mast/ CNPq, 1999
$\mathrm{O}$ ofício de historiador talvez possa ser comparado com aquele do encenador. Tem-se os fatos e os documentos, assim como as peças, até que, em uma nova iniciativa, alguém resolva recontar a história ou resgatar um texto dramatúrgico ao proscênio. Em ambos, a matéria está ali, mas a cada nova interpretação ou encenação tem-se uma nova visão, uma nova problematização, recorte ou idealização, a qual se juntam novos artefatos, sejam documentos, entrevistas ou, no caso do teatro, novos recursos cênicos. Essas 'remontagens' muitas vezes lançam novas perspectivas e entendimentos sobre fatos e textos, ainda não pensados ou vislumbrados, gerando um inesgotável manancial que, no caso da história, forma-se em historiografia.

Recontar a trajetória da formação da física no Brasil e os desdobramentos que levaram à criação do Centro Brasileiro de Pesquisas Físicas (CBPF) e do Conselho Nacional de Pesquisas (CNPq), no ambiente das conseqüências da Segunda Guerra Mundial, tanto no campo internacional quanto no nacional, é o que se propõe a autora da obra em questão. Assim, embora já exista fornida bibliografia sobre o tema e, mais particularmente, sobre a criação do $\mathrm{CNPq}$, o livro de Ana Maria Andrade revela uma nova visão, um novo olhar, ao esmiuçar e tecer as intricadas relações entre militares, cientistas e políticos que levaram à criação dos dois organismos.

A despeito do relativo êxito das pesquisas biológicas no Brasil, desde o início do século XX, a tarefa de fazer ciência no Brasil implicava muito mais um elevado espírito de abnegação e obstinação do que qualquer tipo de apoio. Desde a inexistência de uma política científica nacional 
engendrada pelo Estado, a condição do país de exportador de produtos primários, o bacharelismo das escolas e faculdades que apenas se limitavam a reproduzir saberes mimetizados do Velho Continente até à hipervalorização dos 'doutores' da medicina, engenharia e direito, nada era facilitado aos precursores da atividade científica. Em um país de vasta exploração agrícola, (re)produzia-se conhecimento para uso de uma incipiente camada urbana, que valorizava o dernier cri dos modismos europeus.

E com a física não seria diferente. Assim como a pesquisa biológica só obteve algum tipo de reconhecimento no país após a consagração obtida por Manguinhos na Exposição Internacional de Berlim, em 1907, a física no Brasil apenas alcançou visibilidade e importância após a descoberta e detecção dos mésons- $\pi$ por César Lattes, então um jovem pesquisador de vinte e poucos anos, nos Laboratórios de Bristol, na Inglaterra, em 1947, a partir da observação no estado de natureza. A descoberta dos mésons representava um avanço no conhecimento sobre o estado da técnica da física no mundo, então a ciência do momento graças ao seu emprego na tecnologia nuclear, e seu conseqüente poder de dissuasão após as bombas de Hiroshima e Nagasaki, que encerraram a Segunda Guerra.

Nesse momento, sobre suas cinzas, eclodia a guerra fria entre Estados Unidos e União Soviética, e a corrida armamentista convencional e, principalmente, a nuclear impulsionavam o desenvolvimento da pesquisa em física e da energia atômica, em um cenário de forte paranóia anticomunista no Ocidente.

No Brasil, com a participação da Força Expedicionária Brasileira (FEB) junto aos Aliados na campanha da Itália, o fim da guerra trouxe a redemocratização do sistema político através da anistia, eleições gerais e o governo Dutra, herdeiro de Vargas e do aparato do Estado Novo. Os acordos firmados com os Estados Unidos em troca do esforço de guerra faziam crer que o país se tornaria um aliado preferencial e obteria ajuda americana para seu desenvolvimento. Mas a tarefa de reconstrução da Europa, representada pelo Plano Marshall, visando à contenção da expansão comunista no continente, relegou o país à condição de aliado periférico que, como bem ressalta Ana Maria Andrade, acarretou maiores ganhos para o parceiro mais forte, como a "manutenção da base militar de Fernando de Noronha, o fornecimento de materiais estratégicos", como, por exemplo, o tório - elemento importante para o enriquecimento de urânio -, e outros minerais, presentes nas areias monazíticas, que eram exportadas, na expectativa da cooperação em forma de transferência de tecnologia. E no maniqueísmo da época, graças a um engenhoso ardil, cassava-se o registro do Partido Comunista do Brasil (PCB), no primeiro arranhão na recentemente renascida democracia brasileira.

Nesse panorama, Lattes, logo após a descoberta do mésons- $\pi$, segue para Berkeley, no bojo de seu impacto e, sobretudo, como parte das alianças firmadas entre Brasil e Estados Unidos, razão pela qual um cientista estrangeiro pôde fazer parte de pesquisas consideradas estratégicas para os interesses americanos, cuja Atomic Energy Comisson detinha o poder de liberar ou vetar os trabalhos decorrentes para publicação. Lá, conseguiu reproduzir, em laboratório, a obtenção dos mésons- $\pi$. Reafirmando a consagração obtida em Bristol, o feito de Berkeley redundou em um caudal favorável de outras situações, na criação do CBPF e, logo após, do CNPq. 
E é no capítulo sobre a criação do CBPF que o livro traz algumas interessantes revelações, como, por exemplo, a participação de João Alberto Lins de Barros - o coronel João Alberto, temido chefe da polícia do Distrito Federal no Estado Novo - como um dos principais articuladores e promotores do novo espaço, conseguindo reforços políticos e financeiros. Dois outros irmãos de João Alberto também se envolveram no projeto por interesses profissionais e acadêmicos.

E outra revelação interessante é a de que se tratava de uma instituição de pesquisa que nasceu como fruto de intensa articulação entre pesquisadores, militares, políticos e diversos níveis governamentais, inclusive estaduais e municipais, que subsidiaram a sua fundação e suas atividades iniciais, em 1949, constituindo-se como sociedade civil, sem vínculo direto com o Estado, embora obtendo dotações orçamentárias da União, situação que perduraria até 1976, quando foi incorporado ao CNPq. Evidentemente que o impacto causado pela tecnologia nuclear e a vontade ou necessidade, para uns ou outros, de se alçar o país a um outro patamar além de seu perfil agrícola, propiciou apoios amplos à concretização do CBPF. E ainda, segundo a autora, a física no Brasil, que nasceu com maior vigor na Universidade de São Paulo (USP), quando de sua criação na década de 1930, começou a tomar vulto no CBPF, acarretando inclusive uma migração de alguns pesquisadores e dando origem à rivalidade entre ambas as instituições, além de pesquisadores estrangeiros, sendo que alguns até permaneceram ali definitivamente.

O que, com efeito, vale dizer é que a criação do CBPF e, até mesmo, logo posteriormente, do $\mathrm{CNPq}$, representou a primeira ação organizada e a primeira evidência de sua constituição, da comunidade científica nacional, entendendo-se como tal a defesa de interesses comuns da ciência no Brasil.

A década de 1950 caracterizou-se pela efervescência do debate em torno de concepções distintas de desenvolvimento: o liberalismo clássico, que apregoava o laissez-faire e a importância do capital estrangeiro como fator dinamizador do crescimento econômico; o nacional desenvolvimentismo, baseado no ideário da Comissão Econômica para a América Latina (Cepal) preconizando uma concepção autônoma de desenvolvimento com base no processo de substituição de importações através da absorção de tecnologias; e o desenvolvimentismo nacionalista, caracterizado pela presença forte e efetiva do Estado na economia e investimentos em infra-estrutura industrial e bens de produção.

O segundo governo Vargas (1951-54) seguiria essa terceira perspectiva, marcadamente nacionalista e de grande apelo popular, caracterizada pela criação de empresas estatais voltadas para a geração de insumos industriais e fontes de energia, como Petrobras, Eletrobras, Companhia Siderúrgica Nacional, além de uma agência de fomento para financiar essa empreitada, o Banco Nacional de Desenvolvimento Econômico (BNDE).

Embora ocorrida no final do governo Dutra, mais identificado com o liberalismo econômico, a criação do CNPq em janeiro de 1951, às vésperas da posse de Getúlio Vargas, afinou-se melhor com a perspectiva nacionaldesenvolvimentista desse último. Sua alocação em linha direta com a Presidência da República, sem qualquer interveniência ministerial assim como a composição do Conselho Deliberativo do órgão, integrado por 
cientistas, militares e membros da burocracia governamental, já no governo Vargas, reflete a grande aliança em prol de um desenvolvimento nacional com maior margem de autonomia tecnológica.

Ana Maria Andrade demonstra no capítulo referente à criação do $\mathrm{CNPq}$, que se pode considerar, apesar de curto, um dos melhores textos já produzidos sobre a história do órgão, não obstante os muitos já existentes, como se costurou essa aliança. Inicialmente ainda sob o signo da importância da pesquisa nuclear derivada da guerra, e de se deter esse arsenal tecnológico para se fazer valer no concerto das nações, também é concebido como passível de desempenhar o papel de uma agência de energia atômica, nos moldes da americana. De certa forma, isso desperta um "orgulho nacional", facilitando enormemente sua aceitação nos meios políticos de todos os matizes. Mesmo tendo sua criação motivada pela questão do domínio da tecnologia nuclear, o conselho acaba por amalgamar os diversos segmentos da comunidade científica nacional, tornando-se, apesar de seu caráter governamental, o locus privilegiado de um pacto pelo desenvolvimento nacional, criando os rudimentos de uma política científica nacional.

Nesse capítulo também, a autora descreve mais detidamente a figura e o papel do almirante Álvaro Alberto, elo de ligação e união entre a diversa composição do Conselho Deliberativo do CNPq, por sua condição de militar de alta patente, estreitamente vinculado aos interesses da comunidade científica. Porém, apesar dos objetivos comuns que selaram essa ampla aliança, não deixa de desvelar as dificuldades iniciais de seu funcionamento, a ausência de critérios e parâmetros para a concessão de auxílios e bolsas, o peso dos interesses pessoais na obtenção de bolsas, o poder do lobby dos médicos, por sua tradição para conseguir financiamentos para cursos de aperfeiçoamento que, necessariamente, não guardavam relação com a proposta política do órgão.

Com o suicídio de Vargas em 1954 e a posse de Café Filho, ocorreu uma reviravolta no modelo de industrialização estatista implantado na primeira metade da década de 1950 , do qual não saiu ileso o conselho. Embora a autora considere que as dificuldades com as quais se defrontou o CNPq dali por diante se devessem à crise econômica do país e às dificuldades monetárias do período, vale dizer que outros autores atribuem o esvaziamento do órgão à própria reorientação da política econômica a partir de então. O governo Kubitschek, o qual optou por um processo de crescimento acelerado - cinqüenta anos em cinco - e redirecionou a política industrial para o setor de bens de consumo, através da substituição de importações e da participação do capital estrangeiro, levou ao desmantelamento da proposta varguista de um modelo autônomo de industrialização e, conseqüentemente, ao fim da aliança que forjou o CNPq. Seu esvaziamento tornou-se inevitável, tanto que a proposta de criação de um Ministério da Ciência, apoiada por diversos institutos de pesquisa e a Sociedade Brasileira para o Progresso da Ciência (SBPC), acabou natimorta por falta de apoio político no governo JK.

E tal esvaziamento também pode ser explicado por um caso por poucos conhecido e, que, segundo revela a autora, tomou proporções de escândalo, podendo ter contribuído para seu enfraquecimento e pondo fim ao sonho de tornar o Brasil detentor de tecnologia nuclear. 
Trata-se da compra, de dois sincrociclótons, primeiro um de menor porte e, posteriormente, outro maior, equipamento importante para a consolidação da pesquisa em física no Brasil e para o domínio de tecnologia atômica. Um caso que se arrastaria de 1949 a 1960, em que se envolveram cientistas, políticos e militares, financiamentos perdidos, interesses internacionais em jogo, revelando a ausência de planejamento da pesquisa, a capacitação de recursos humanos, a ingenuidade nacional frente aos interesses americanos, causando uma fissura tamanha nas relações pessoais entre pesquisadores e entre o CBPF e o $\mathrm{CNPq}$, acrescida de desvio de verbas e corrupção, que acabaram por respingar no almirante Álvaro Alberto, sendo, segundo a autora, a causa de sua demissão da presidência do CNPq. Ao cabo de 11 anos, viu-se a perspectiva da capacitação tecnológica nuclear nacional esvair-se mais uma vez: no meio do caminho abandonou-se a proposta do sincrociclóton maior e, quando finalmente inaugurou-se o de menor proporção, descobriu-se a inutilidade de seu emprego.

Mesmo que apenas pelo relato desse caso, que aqui evita-se contá-lo em detalhes para instigar a curiosidade do leitor, vale a pena debruçar-se sobre o livro de Ana Maria Andrade. Nele pode-se entender por que, às vezes, mesmo se tendo condições favoráveis, poucas vezes bem entendido, torna-se difícil fazer ciência e, principalmente, apresentar resultados palpáveis e tangíveis à sociedade, na busca de sua legitimação.

Portanto, Ana Maria Andrade resgata a história da construção de uma comunidade científica, de sua capacidade de articulação e mobilização de diversos setores da sociedade e do Estado em um livro que, ressaltese, profundamente bem documentado, tanto em fontes textuais e iconográficas, apenas carente de um glossário de termos de física, necessário aos leigos, nos faz pensar que ciência exige planejamento, avaliação e, fundamentalmente, perspicácia política e uma profunda compreensão do meio na qual a atividade científica se insere, em todas as suas dimensões: política, econômica, social e tecnológica.

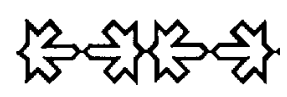




\title{
Rodolfo Teófilo e a luta contra a varíola no Ceará, 1905
}

\author{
Rodolfo Teófilo and the combat against \\ smallpox in Ceará, 1905 \\ Nathacha Regazzini Bianchi Reis \\ Graduada em história \\ Praia do Flamengo, 122/608 \\ 22210-030 Rio de Janeiro - RJ Brasil \\ nathacha_@hotmail.com
}

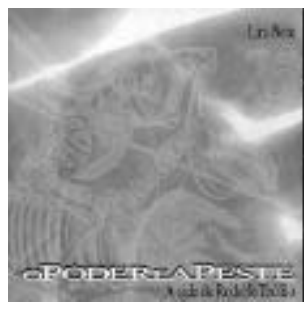

Lira Neto

O poder e a peste

Fortaleza, Fundação

Demócrito Rocha,

1999, 223p.
A produção editorial acerca da história da saúde pública no Brasil tem sido bastante expressiva nas duas últimas décadas. O tema vem sendo visitado freqüentemente por cientistas sociais e historiadores, psicólogos e médicos, preocupados tanto com questões mais localizadas, como também o surgimento de amplos debates sobre o papel do Estado nas políticas públicas de saúde. Vale ressaltar que há muitas publicações acerca de epidemias de febre amarela, cólera e varíola no século XIX, e as ações de médicos, farmacêuticos e autoridades governamentais, já no século XX, todos empenhados em combatê-las (Chaloub, 1996; Hochman, 1998; Beltrão, 1999; Fernandes, 1999).

O livro do jornalista Lira Neto é mais uma excelente iniciativa em ambas as direções. Conta a história do farmacêutico baiano Rodolfo Marcos Teófilo (1853-1932), e sua trajetória junto à população da cidade de Fortaleza, assolada por sucessivas epidemias de cólera e varíola, ao longo da segunda metade do século XIX.

Feliz combinação de biografia e narrativa histórico-jornalística, com alguns toques de um agradável estilo ficcional, este trabalho é fruto de três anos de pesquisa do autor, a partir de inusitada descoberta. Em 1994, em decorrência de obras públicas de saneamento no bairro de Jacareacanga, Fortaleza, operários que ali trabalhavam encontraram centenas de ossadas humanas, dispostas em vala comum e cova rasa. As imagens veiculadas em jornal faziam lembrar um típico campo de concentração nazista, e o fato permaneceu durante algum tempo como um enigma para a imprensa e a sociedade local. Depois de inúmeras conjecturas as mais absurdas, chegou-se enfim à verdadeira explicação. Tratava-se de uma espécie de "cemitério clandestino". Na verdade, foi a solução mais prática encontrada por coveiros em fins do século XIX, para dar conta de milhares de corpos, das dezenas de mortos, a cada dia naquela cidade. Fortaleza já vinha de um histórico de sucessivas epidemias de cólera e febre amarela, tendo ambas as doenças produzido efeitos devastadores na cidade. Em fins do século XIX, foi a doença mais tarde conhecida como varíola e causada pelo agente transmissor Culex, a 'peste' que arrasaria boa parte da população cearense, pois, em vez de se restringir à capital, também se espalharia por municípios vizinhos, como Pacatuba.

Elucidado o mistério que cercou a descoberta daquela montanha de ossos humanos, Lira Neto empreendeu uma pesquisa extensa, que classificou como 'arqueológica'. O objetivo principal foi examinar a trajetória do farmacêutico Rodolfo Teófilo, sua profissão, sua visão de mundo e 
sua contribuição para a história do Ceará. O livro é dividido em 23 capítulos, sendo que metade dos quais versa sobre importantes momentos da história política e das condições sanitárias do Ceará, assolado em todo século XIX por epidemias de cólera, varíola e febre amarela. A edição está especialmente enriquecida pelas muitas notas explicativas dispostas nas laterais das páginas, além de inúmeras ilustrações iconográficas.

A então província cearense passou por verdadeiras situações-limite, como, por exemplo, o dia 28 de novembro de 1868, quando morreram nada menos que mil pessoas na capital, vítimas da varíola, que não poupara nem mesmo a mulher do então presidente da província. A data ficou conhecida como o Dia dos Mil Mortos. Os cadáveres eram empilhados sem qualquer medida de higiene, e depois transportados em carroças por coveiros completamente embriagados de cachaça. As ingestões maciças da bebida eram uma forma de evitar o mal-estar causado pelo terrível odor dos corpos tomados pelas pústulas.

Passados quase quarenta anos, a cidade mergulharia em mais um caos epidemiológico. Dessa vez, era a varíola, o mal que no mesmo ano de 1905 acometia a capital federal, vitimando milhares e alastrando-se vorazmente pela população. O redimensionamento dos espaços urbanos, o crescimento desordenado e as péssimas condições de higiene e saneamento das cidades foram fatores que se conjugavam fastidiosamente, culminando em quadros caóticos de calamidade pública.

A dinâmica que envolveu todas as ações de médicos, cientistas e farmacêuticos no combate aos surtos epidêmicos representou um marco na história da ciência no Brasil. Estudos historiográficos recentes já permitem perceber, em fins do século XIX, o desenvolvimento de novas concepções acerca das formas de transmissão, profilaxia e tratamento vacínico (Benchimol, 2000). Embora não seja possível estabelecer rupturas definitivas, o saber científico começou a se dissociar dos pressupostos positivistas, quando os médicos começaram a desenvolver pesquisas individuais em torno dos agentes causadores de doenças, e sobretudo buscaram encontrar fórmulas que pudessem levar à produção de antídotos.

Rodolfo Teófilo, farmacêutico de formação, seria um típico higienista. A descrição de Jaime Benchimol (op. cit., p. 14) para os médicos do Rio de Janeiro no século XIX lhe cairia muito bem: aquele "cuja prática tem a ver com a prevenção ou o combate da doença enquanto fenômeno coletivo, e cuja reflexão está voltada para as causas, cósmicas e sóciohistóricas, das epidemias e os obstáculos que impedem a neutralização dessas causas". Também faria as vezes de clínico, mas a maior parte de suas ações consistia nas atividades de profilaxia. Assim, foram grandes os esforços empreendidos por Rodolfo Teófilo para conter a epidemia de varíola em sua província. As ações compreendiam desde a compra de animais para o processo de produção das vacinas a viagens a cavalo pela periferia de Fortaleza, para fazer as aplicações, passando pelo emprego de um carismático poder de persuasão. Com o objetivo de convencer os moradores pobres das favelas de que eles deveriam permitir-se vacinar, o farmacêutico, imbuído de um espírito criativo, inventou a figura de são Jenner, na verdade, Edward Jenner, que em fins do século XVIII descobriu a vacina contra a varíola. Fundador da Liga Cearense contra a Varíola, Teófilo distribuiu suas vacinas pelo interior do estado, chegando a gastar 
o próprio dinheiro com a produção dos antídotos. Sofreu forte reação da elite local, incomodada com a ascensão do farmacêutico. Este incômodo refletiu-se diretamente na imprensa local, que começou a publicar verdadeiros ataques à vacina produzida por ele, sugerindo que a mesma teria causado a morte de várias crianças na capital. A resposta não tardou a chegar. Em 1907, Teófilo recebia a aprovação da vacina pelo Instituto Oswaldo Cruz (IOC), então denominado Instituto de Patologia Experimental de Manguinhos, no Rio de Janeiro. Debelada a varíola, o farmacêutico ainda sofreria retaliações do governo, não obtendo apoio, em momento algum, das autoridades municipais ou provinciais.

A iniciativa de Lira Neto é de grande valia para todos os pesquisadores preocupados com questões pertinentes ao universo da saúde pública no Brasil, e seu maior mérito é justamente o de lançar luz sobre as estratégias de erradicação, lutas e tensões de poder, presentes no cenário da capital cearense em fins do século XIX. Cabem aqui algumas observações quanto à maneira com que Lira Neto encaminhou sua narrativa ao se empenhar no objetivo de biografar Rodolfo Teófilo.

Figura da ilustre elite provincial do Ceará, Teófilo foi um homem preocupado com a pobreza e a degradação humana que atingiam as populações pobres na capital e nos municípios vizinhos. São igualmente louváveis seus esforços em conscientizar essas populações de que elas deveriam ser vacinadas. Em última análise, a caracterização que o autor confere ao 'higienista' Rodolfo Téofilo, qual seja, a de um lutador incansável pelo bem-estar de seu povo, parece aproximar-se de uma visão messiânica. Penso que tal visão deve ser relativizada, face às históricas condições efetivas de se empreender uma campanha de erradicação, se considerarmos todas as dificuldades de ordem socioeconômicas que o farmacêutico teve que enfrentar.

Outra conotação que o autor tributa a Teófilo é a de um intelectual avant-garde, despido das idéias evolucionistas herdadas do pensamento spenceriano. Mas durante o desenvolvimento da leitura, pode-se perceber que o "esclarecimento" terminava no ceticismo de Téofilo quanto às reais possibilidades de redenção das populações pobres da cidade. É impossível, portanto, dissociar o higienista de seu tempo, implicando-se aí todas as conotações imagináveis que o clássico positivismo conferia às categorias científicas profissionais na segunda metade do século XIX.

Exceto o fascínio que a vida de Rodolfo Teófilo exerceu sobre Lira Neto, esfumaçando um pouco seu perfil político e intelectual, a narrativa leve, e ao mesmo tempo densa, cobre um capítulo importante e desconhecido da história da saúde pública no Ceará. Sem adquirir um tom exagerado de efeméride, $\mathrm{O}$ poder e a peste faz justiça a um personagem notável na história das lutas pela erradicação das doenças no Brasil. 


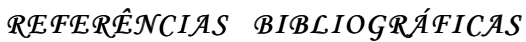

Beltrão, Jane Felipe Cólera, o flagelo da Belém do Grão-Pará.

1999 Tese de doutoramento, Campinas, Unicamp.

Benchimol, Jaime Larry Dos micróbios aos mosquitos: febre amarela e a revolução pasteuriana 2000 no Brasil. Rio de Janeiro, Editora UFRJ/Fiocruz.

Chaloub, Sidney

Cidade febril: cortiços e epidemias na corte imperial.

1996

São Paulo, Companhia das Letras.

Fernandes, Tania $\mathcal{M}$.

Vacina antivariólica: ciência, técnicas e poder dos homens (1808-1920). 1999 Rio de Janeiro, Editora Fiocruz.

Hochman, Gilberto 1998

A era do saneamento: as bases da política de saúde no Brasil.

São Paulo, Hucitec/Anpocs.

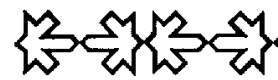

